\title{
The impact of a therapeutic exercise intervention on depression and body self-image in HIV-positive women in sub-Saharan Africa
}

This article was published in the following Dove Press journal: HIVIAIDS - Research and Palliative Care

\author{
Andrea K Daniels' \\ Rudolph L Van Niekerk ${ }^{2}$ \\ 'School of Community Psycho- \\ social Research (COMPRES), Faculty \\ of Health Sciences, North West \\ University, Potchefstroom, South \\ Africa; ${ }^{2}$ Department of Human \\ Movement Science, Faculty of Health \\ Sciences, University of Fort Hare, \\ Alice, South Africa
}

Video abstract

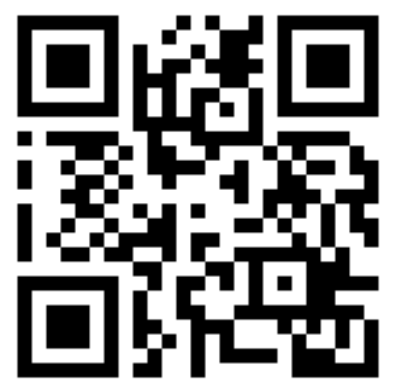

Point your SmartPhone at the code above. If you have a QR code reader the video abstract will appear. Or use: http://youtu.be/GDRmcoi7WCU

\begin{abstract}
Introduction: Attitudes, responses, and reactions of HIV-positive women in three sub-Saharan African regions toward a therapeutic exercise intervention, aimed to determine the presence of depression and low body self-image, were captured. This provided insight into body satisfaction and desire to exercise (Stage 1, $n=60$ ), body self-image and depression (Stage 2, $n=60$ ), and overall concerns around the often adverse side effects of antiretroviral treatment (ART). A program of therapeutic (specialty) exercise was developed for the experimental design (Stage 2), to quantify the psychological side effects of these variables.

Methodology: Stage 1 constituted a qualitative exploration into attitudes and perceptions around ART, toxicity, health concerns, metabolic irregularities (lipodystrophy), body shape and size dissatisfaction, and cultural attitudes toward exercise. This stage deployed brief informal face-to-face interviews, based on the World Health Organization (WHO)/United Nations Fund for Population Activities (UNFPA) AIDS Inventory, in three sub-Saharan African regions (including provincial and district hospitals, nongovernmental organizations, voluntary counseling and testing/HIV and testing centers, and primary care outpatient clinics). Stage 2 of the study comprised a quantitative experimental design, conducted on a sample of HIV-positive women (mean age $=39.0$ years; mean years on $\mathrm{ART}=5.5 ; 86 \%$ black) in three selected HIV outpatient clinics in Johannesburg, South Africa.

Data analysis: The collated data sets from both stages of the research were presented, analyzed, and interpreted (thematic analyses [Stage 1] and statistical analyses [Stage 2]) using the body self-image questionnaire and Beck's depression inventory.

Results: Stage 1 outlined participants' concerns and reports around 1) body shape and size, including long-term effects of ART and 2) attitudes toward exercise, as a function of HIV status. Stage 2 represented pre- and posttest statistics, showing low statistical means for both the experiment and the control groups, with statistical significance for four out of nine items of subscales of body self-image questionnaire.
\end{abstract}

Keywords: antiretroviral treatment, ART, body self-image, depression, functional cognition, lipodystrophy, therapeutic movement

\section{Introduction}

AIDS has, in recent decades, gained a global epidemiological priority, with an estimated 34 million people testing positive for HIV, while 2.5 million have developed related symptoms and syndromes of the disease. ${ }^{30,41}$ HIV-positive prevalence in subSaharan Africa currently lies at about $21.5 \%$, mainly concentrated among resourcestrapped and marginalized sectors of the population. South Africa remains one of the regions to show highest profiled incidences of HIV in the world, with an estimated
Correspondence: Andrea K Daniels North West University, Building E8, Hoffman Street, Potchefstroom 2520, South Africa

Tel +27 07I 0326288

Email andrea_daniels@hotmail.com 
7.1 million people living with HIV (PLHIV) in 2016. South Africa accounts for a third of all new HIV infections in Southern Africa. ${ }^{3}$

\section{The impact of stigma, prejudice, and violence on the mental health of HIV- positive women}

Along with pervasive stigma and prejudice toward HIV sufferers in general, it was found that women are particularly vulnerable to the negative impact of the disease, from a psychosocial perspective. ${ }^{8,22,30}$ The 2015 South African National AIDS Council Report ${ }^{34}$ shows that internalized stigma is still a major challenge in South Africa, with more than $40 \%$ of PL HIV expressing feelings of internalized stigma. This has resulted in a call for more sophisticated treatment and complementary care measures. ${ }^{39}$ In addition to these challenges, HIV-positive women are seen to be at risk of violence, ${ }^{3}$ factoring in the dominant patriarchal culture and society in many African countries. A study on violence and HIV among women in Tanzania found the odds of reporting partner violence to be $30 \%$ higher among younger HIV+ women than among younger HIV-negative women. ${ }^{3}$ Orza et al illustrate how the plight of HIV-positive women affects their mental health, as well as their sexual and reproductive health and overall human rights. ${ }^{27}$ This is exacerbated by their economic circumstances such as their capacity to access and adhere to adequate health care and medication. Orza et al posit that these intersecting issues are not addressed systemically. ${ }^{27}$ Given that psychiatric symptoms, particularly depression, and psychopathologies are widespread among pregnant women living with HIV, there is clearly a need for mental health issues to feature in global transmission guidelines. ${ }^{11}$

\section{The pros and cons of antiretroviral treatment (ART)}

With the continuing rollouts of more sophisticated ART, HIV can now be managed as a chronic and stable condition as opposed to a progressive disease..$^{22}$ Despite this, however, HIV-positive individuals are still impacted by the often debilitating collateral side effects (toxicity, metabolic irregularities such as lipodystrophy, diabetes, toxic rashes, nausea, and hypertension) associated with the treatment. ${ }^{3,9,10,16}$ These side effects may further impact the mental health of this population, ${ }^{38}$ leading to low self-image and even depression. ${ }^{26}$ The study provided some insight into current treatment and complementary care modalities for HIVrelated depression and dissatisfaction with body shape and size (body self-image), ${ }^{36,37}$ including cognitive-behavioral therapies and therapeutic exercise. Evidence was provided to show that the range of physical side effects and related toxicities burdening this population leaves them at risk of further disability if the right type of exercise or therapy is not prescribed.

\section{The benefits of exercise for HIV-infected individuals}

Research shows that the pervasive physical and psychological side effects and health risks, which are a function of chronic ART, ${ }^{16}$ warrant an increasing demand for more sophisticated ART. Synchronous to this, there is evidence of a growing need for high-quality complementary care programs to manage and alleviate some of these side effects across the continuum of HIV care. ${ }^{14,43,36}$ According to global health mandates of the World Health Organization (WHO) ${ }^{45,46}$ and UNICEF, ${ }^{39}$ it is vital that HIV-positive and all diseased populations are offered accessible incentives to manage their disease and to increase their knowledge of the link between exercise and mental health in HIV. Strategies for dealing with the direct effects of HIV and the secondary effects of ART include exercise. Exercise has been shown to provide many health benefits, ranging from increased aerobic capacity to mood improvement. ${ }^{20}$

\section{Exercise type for HIV-infected individuals}

From a control perspective, taking into account toxicity, metabolic syndromes, hypertension, and cardiac stress, it was decided that a structured, low impact therapeutic exercise modality would be deployed for this population. Movement and exercise therapy have gained increasing support as alternative healing modalities, over the past 50 years, ${ }^{44}$ especially with regard to positive behavioral reinforcement and cognitive self-representations. ${ }^{25,38}$ In addition to this, therapeutic exercise has been found to increase functional capacity in HIV-infected individuals, as it offers the client both cognitive and physical solutions. ${ }^{32}$ Although research in these areas is limited, it is, however, apparent that therapeutic exercise is synchronously becoming an accepted alternative care modality for HIV/AIDS sufferers. ${ }^{20,21,34}$ Figure 1 depicts the potential for transference and behavioral reinforcement, which a structured program of therapeutic exercise can elicit.

\section{Problem statement and objectives of the study}

The aims and objectives of this study were: 1) to implement a structured customized-to-HIV/AIDS psychotherapeutic 


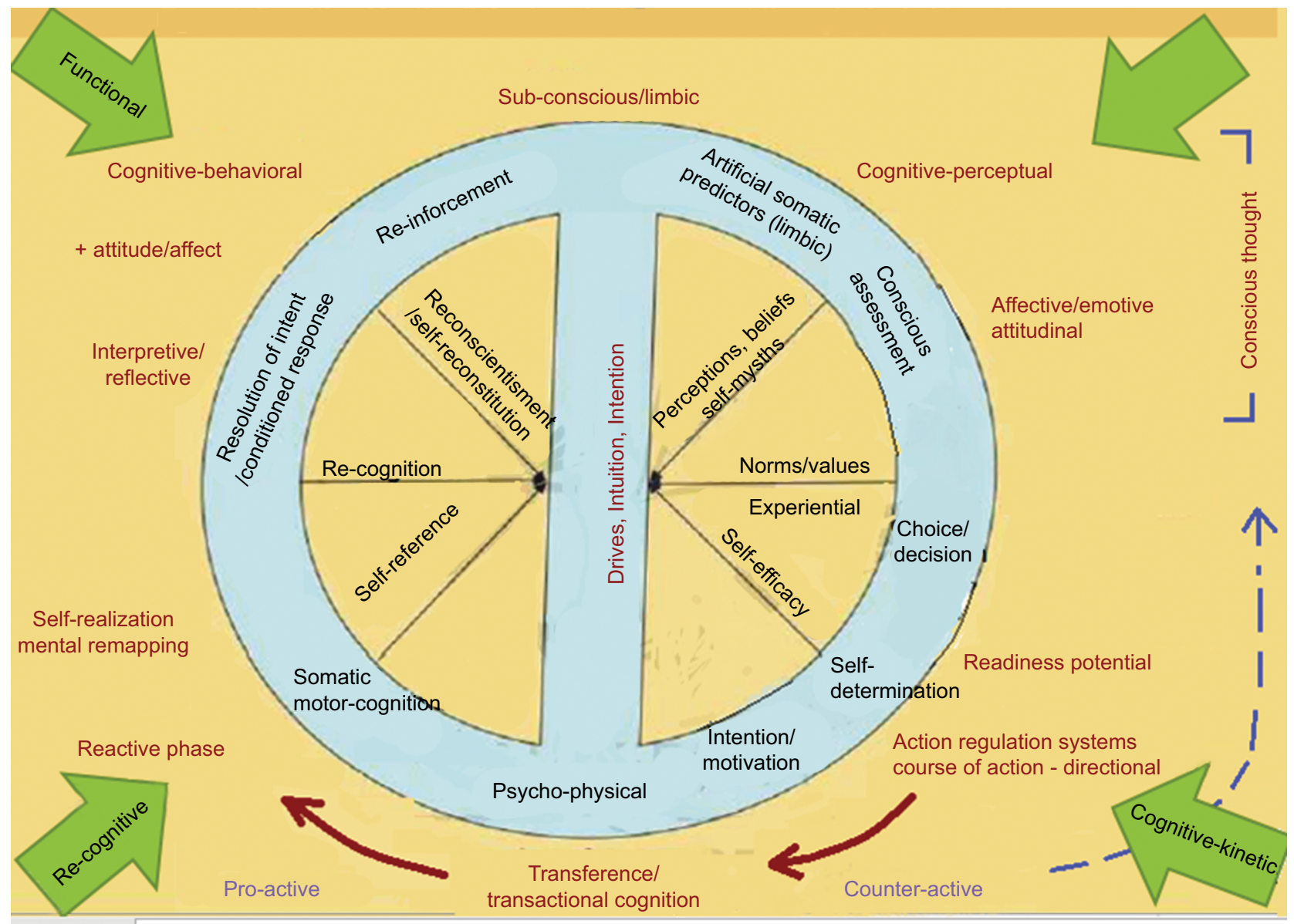

Figure I Cognitive kinetics: behavioral reinforcement through physical transference.

exercise intervention to a sample (Stage 1: $n=60$; Stage 2: $\mathrm{n}=60$ ) of women infected with the HIV virus in sub-Saharan Africa, in order to determine changes in instances of depression and body self-image and 2) to both qualitatively and quantitatively measure (utilizing selected screening instruments) and determine the differences in depression and body self-image before and after the therapeutic exercise intervention, while taking into account the constraints of disability in this population.

\section{Methodology}

\section{Stage I}

Stage 1 of this study comprised a qualitative study, comprising brief (informal face-to-face interviews) in three sub-Saharan African countries (SSA) (Kenya, Zambia, and Malawi), where participants $(n=60)$ originated from cultures such as the Kenyan Masaai, who spoke a range of African dialects (Swahili, Bemba, Tswana, Zulu, Afrikaans, and other). These interviews were conducted at provincial and district hospitals (Narok Maasai District hospital, Kenya), the Pillar of Hope VCT testing center (Narok, Kenya), and the Kara Counseling center (Lusaka, Zambia). Officials at each of these facilities signed approval for the intervention, with participant consent for Stage 1 being written and informed.

\section{Sample}

A sample of 60 randomly selected participants was established for Stage 1. Subjects were volunteers recruited from among the patients who attended the various health care and voluntary counseling and HIV testing centers, ranging across urban, peri-urban, and rural areas of the various countries.

Stage 1 was conducted by means of screening participants with regards to:

1. Their overall physical health based on the WHO/UNFPA AIDS Inventory, ${ }^{45}$ including experienced side effects, such as toxicity, cardiovascular, ${ }^{16,17}$ pain, ${ }^{4}$ inflammation, ${ }^{7,2}$ cramps, metabolic irregularities, lipodystrophy, ${ }^{15}$ rashes, 
Table I Results of brief interviews (based on WHO/UNFPA AIDS Inventory ${ }^{45}$ )

\begin{tabular}{|c|c|c|c|}
\hline $\begin{array}{l}\text { Participant } \\
\text { experience of } \\
\text { ART }\end{array}$ & $\begin{array}{l}\text { Kara Counseling Center, Lusaka } \\
(\mathrm{n}=20)\end{array}$ & $\begin{array}{l}\text { Narok District Hospital/Pillar of } \\
\text { Hope NGO (combined) } \\
(\mathrm{n}=20)\end{array}$ & $\begin{array}{l}\text { Malawi HTC Clinic, Nkhata Bay } \\
(\mathrm{n}=20)\end{array}$ \\
\hline Mean years on ART & 4 & 5 & 7 \\
\hline $\begin{array}{l}\text { Attitude regarding } \\
\text { ART }\end{array}$ & $75 \%$ positive & $90 \%$ positive & $85 \%$ positive \\
\hline Physical fitness & $\begin{array}{l}\mathrm{N}=10(50 \%) \text { reported overall improved } \\
\text { physical condition }\end{array}$ & $\begin{array}{l}\mathrm{N}=14(70 \%) \text { reported overall improved } \\
\text { physical condition } \\
\mathrm{N}=I(5 \%) \text { in wheelchair as a result of TB } \\
\text { of spine, yet physically able and willing } \\
\text { to participate in movement program }\end{array}$ & $\begin{array}{l}\mathrm{N}=9(45 \%) \text { reported overall improved } \\
\text { physical condition }\end{array}$ \\
\hline Pain/cramps & $\mathrm{N}=3(15 \%)$ & $\mathrm{N}=\mathrm{I}(5 \%)$ & $\mathrm{N}=3(15 \%)$ \\
\hline $\begin{array}{l}\text { Metabolic fat } \\
\text { (lipodystrophy) }\end{array}$ & $\begin{array}{l}\mathrm{N}=5(25 \%) \text { respondents reported } \\
\text { metabolic complications (lipodystrophy, } \\
\text { in particular buffalo hump) }\end{array}$ & $\begin{array}{l}\mathrm{N}=9(45 \%) \text { respondents reported some } \\
\text { form of metabolic disorder }\end{array}$ & $\begin{array}{l}\mathrm{N}=6(30 \%) \text { respondents reported } \\
\text { metabolic complications (lipodystrophy } \\
\text { in particular buffalo hump) }\end{array}$ \\
\hline Infections/flu & $\mathrm{N}=2(10 \%)$ & $\mathrm{N}=3(15 \%)$ & $\mathrm{N}=4(20 \%)$ \\
\hline Fatigue & $\mathrm{N}=7(35 \%)$ & $\mathrm{N}=2(10 \%)$ & $\mathrm{N}=4(20 \%)$ \\
\hline Heart problems & $\mathrm{N}=2(10 \%)$ & $\mathrm{N}=\mathrm{I}(5 \%)$ & $\mathrm{N}=3(15 \%)$ \\
\hline Nausea/vomiting & $\mathrm{N}=5(25 \%)$ & $\mathrm{N}=6(30 \%)$ & $\mathrm{N}=3(15 \%)$ \\
\hline Depression & $\mathrm{N}=2(10 \%)$ & $\mathrm{N}=\mathrm{I}(5 \%)$ & $\mathrm{N}=5(25 \%)$ \\
\hline Sweating & $\begin{array}{l}\mathrm{N}=3(\mathrm{I} \%) \text { respondents reported } \\
\text { sweating after being on the single-dose } \\
\text { ARV }\end{array}$ & $\begin{array}{l}\mathrm{N}=3(\mathrm{I} \%) \text { respondents reported } \\
\text { sweating after being on the single-dose } \\
\text { ARV }\end{array}$ & $\begin{array}{l}\mathrm{N}=6(30 \%) \text { respondents reported } \\
\text { sweating after being on the single-dose } \\
\text { ARV }\end{array}$ \\
\hline Amnesia & $\begin{array}{l}\mathrm{N}=5(25 \%) \text { reported feeling forgetful } \\
\text { or lapse in short-term memory }\end{array}$ & $\begin{array}{l}\mathrm{N}=4(20 \%) \text { reported feeling forgetful or } \\
\text { lapse in short-term memory }\end{array}$ & $\begin{array}{l}\mathrm{N}=4(20 \%) \text { reported feeling forgetful or } \\
\text { lapse in short-term memory }\end{array}$ \\
\hline
\end{tabular}

Abbreviations: UNFPA, United Nations Fund for Population Activities; NGO, nongovernment organization; ART, antiretroviral treatment; TB, tuberculosis; ARV, antiretroviral.

fatigue, and other psychophysical disorders, as shown in Table $1 .^{2}$ These side effects were identified, tabled, and the frequencies noted.

2. Feelings about their status in terms of stigma.

3. Feelings about their bodies, attitudes to exercise, and current exercise behaviors.

At this stage of the research, no exercise intervention was presented at the clinics to help patients deal with these issues. Participants were merely asked questions about their attitudes to their bodies, in light of their HIV status, whether they were happy with their overall appearance (including weight, body shape, and size), and around attitudes and feelings toward exercise (keenness, willingness). Where language posed a problem, interviews were directly interpreted by monitors and clinic staff at the various centers. Approval for the intervention was signed off by the ethics committee of the City of Johannesburg Primary Care clinics, by M Maepa (Regional Director, Region B Health).

\section{Stage 2}

Stage 2 of the study comprised a quantitative experimental design, conducted on a sample of 60 randomly selected HIV-positive women in three selected HIV outpatient clinics in South Africa. Participants had a mean age of 39 years, had been receiving ART for a means of 5.5 years, and were $86 \%$ black. All participants were asked to complete the respective self-report screening questionnaires and signed consent to participate in the 6-week exercise intervention, ensuring that the participants' consent was written and informed. The respective measuring instruments detailed personal and biographical information about each participant.

\section{Patients and materials}

The collated data sets from both stages of the research were presented, analyzed, and interpreted using the Beck's depression inventory (BDI) ${ }^{6}$ and the body self-image questionnaire (BSIQ) ${ }^{33}$ The researcher maintained ethical and procedural cognizance of the fact that both questionnaires were standardized American measuring instruments, unadapted for developing countries. Logbooks and guide books were given to the experiment group. Reading material was given to the control group.

The 6-week exercise intervention was initiated after both groups (experiment and control) had completed the two questionnaires. Variables that were factored in to the program included timing (speed of movement), technique (when, how, style), and degree of intensity (light, heavy). 
Participants of the experimental group were shown how to warm up and cool down and how to avoid overexertion. Then, the participants took the exercise booklet home and agreed to conduct the prescribed exercises at the same day/evening, twice a week. They were asked to log their exercise output in a logbook and to weigh and measure their waistline and hip circumference at the end of each week. The control group was asked to read the prescribed material. Participants then returned to the clinic after the 6-week time frame and submitted their booklets. Both groups subsequently completed the two questionnaires for posttest.

\section{Data collection and analysis}

Data were analyzed using both descriptive and inferential statistics (including parametric and nonparametric).

\section{Data analysis for Stage I}

The research results for Stage 1 were initially presented as an analysis of the qualitative data obtained from the individual semi-structured interviews. It was intended that the results of the qualitative data would contribute toward the development of the quantitative methodology for Stage 2 of the study, based on the specific needs of HIV-positive individuals receiving ART. The qualitative data obtained in Stage 1 were not subjected to coding or thematic analysis per se, although reports were collated and frequencies noted in terms of participants' reported experience of side effects and their attitudes to exercise and willingness to engage in a specialty complementary care program of this kind. Summations were made around overall statements around side effects, general health, and well-being, based on the WHO AIDS Inventory. ${ }^{46}$

The WHO/UNFPA AIDS Inventory ${ }^{46}$ attempts to define dimensions of HIV-specific disability. The purpose of these measuring instruments was to evaluate the extent to which HIV-specific measuring instruments capture disability experienced by adults living with $\mathrm{HIV},{ }^{33}$ while O'Brien et $\mathrm{al}^{23}$ developed a conceptual framework of disability from the perspective of adults living with HIV, attempting to define some of the health-related challenges, the physical, social, and psychological areas of their life affected, and the impact of these challenges on their overall health. O'Brien et al's ${ }^{23}$ resulting Episodic Disability Framework conceptualizes disability as multi-dimensional and episodic in nature. The framework is comprised of three main components:

1. dimensions of disability,

2. contextual factors that may exacerbate or alleviate disability, and
3. triggers or life events that may initiate a major or momentous episode for adults living with HIV.

Within this context of participants reporting the various side effects and disease complications, related constructs included health status indicators, quality of life, disability evaluation, behavior and behavior mechanisms, activities of daily living, mental wellness, work, socioeconomic factors, signs and symptoms, mental disorders, uncertainty, culture, family, social environment, social isolation (due to stigma), and general socialization (including recreational activities such as exercise).

For this study, questions on physical health and related side effects were thus incorporated from the abovementioned frameworks, which detail reports of previous exercise behaviors, history (year diagnosed), and treatment of disease, including medically diagnosed symptoms and current/previous chronic side effects. Participants were screened and interviewed as per the WHO/UNFPA AIDS Inventory. ${ }^{46}$

\section{Results}

After the data sets for the two stages of the research were collated (Stage 1, thematically analyzed and Stage 2, statistical analysis utilizing SPSS [SPSS Inc., Chicago, IL, USA]), results for the two stages were rendered as follows.

\section{Results for Stage I}

1. The health-related questions identified current treatment programs at the different clinics and the medical symptoms reported by the participants on antiretroviral (ARV) treatment.

2. Questions pertaining to participant's HIV status, in terms of stigma, showed that most did not find stigma to be an overriding problem. Reports that did show feelings around stigma included insecurity at the workplace and concerns about children.

3. The questions pertaining to attitudes about their bodies, including exercise behaviors of the various themes, such as physical fitness and willingness to engage in exercise, were identified and the frequencies scored.

The results of the self-reported perceptions, feelings, and attitudes toward the various topics indicated the following:

1. That participants had sufficient knowledge about their physical wellness, including the side effects, with an even distribution of reports in the various sub-Saharan countries. The highest number of reports comprised the presence and concerns around body shape, body image, and lipodystrophy. 
2. As discussed, participants' attitudes and feelings around stigma were not conclusive to stigma per se (supported by recent research that stigma does not factor as a negative construct in HIV-positive populations).

3. With regards to the attitudes and feeling about exercise and feeling physically fit, it was also found that, in addition to existing comprehensive care and counseling treatment programs, many of the women interviewed, although feeling healthy and strong, were leading sedentary lifestyles and were unsure how to adopt or implement an appropriate exercise modality which might improve their body shape and fitness levels. Although this group did not participate in the exercise program per se, they expressed enthusiasm at the suggestion of customized exercise programs at their local outpatient centers. However, in addition to this, many participants were apprehensive about exercising in terms of their cultural practices and were not sure if this was something they would really do.

4. With regards to expressing their feelings around depression or poor body self-image, participants were not clear and struggled to express themselves. Similarly, with regards to some of the physical side effects (toxicity) they were experiencing, they also struggled to express what they believed to be happening to their bodies.

These conflicting attitudes toward exercise were verbalized by some of the participants as follows:

Int 1: Purity (not her real name: fruit seller) - downtown Lusaka:

Yes. I am feeling very happy now that I am taking my medication. I am now putting on weight and have no side effects from the ARVs. But I would like to exercise, you see (points around at other fruit sellers, her daughter sitting at her feet) we are just sitting here all day and not exercising.

Int 2: Jocinta (not her real name) - Narok Maasai County District Hospital:

I do have problems with my stomach (points to swollen abdominal area) and my breasts have become very large. I am not happy about his and want you to show me exercise to make this go away.

The Maasai women interviewed at this hospital were predominantly from rural settings, appeared to be more subdued, and less forthcoming regarding their circumstances, while poverty and prevailing stigma surrounding their disease status appeared to be a factor which contributed toward concerns about their children, adding to low self-esteem and depression.
Int 3: Gracious (not her real name) - Crosby Clinic, Johannesburg, SA:

I have rashes on my (buttocks, shows rash) and dryness and cramps in my feet. Also my stomach is swollen and lower legs are too thin. I am going to the gym, but it is not helping. Please can you show me how I can make this better.

Int 4: Fredah (not her real name) - Nkhata Bay, HIV counselling and testing outpatient center:

I don't have any side effects and feel very strong on the medication. I don't exercise but would like to in order to stay healthy and build more muscle. No, I have no fatigue or memory loss, and in fact my mind feels much clearer. I am also planning to study law.

From a cultural perspective, a percentage of these women (57\%) walked (often great distances) and were actively engaged in physical work (piece jobs, kitchen staff, agricultural labor, and other) but still expressed the desire to engage in alternative and more proactive forms of physical exercise. Conversely, a significant number of participants (53\%) reported having a sedentary lifestyle and did not have any previous or current exercise history. It was therefore ascertained that there was a need to define a structured movement rather than exercise intervention - for PLHIV. In addition to existing comprehensive care and counseling treatment programs, many of the women interviewed, although feeling healthy and strong, were leading sedentary lifestyles and were unsure of an appropriate exercise modality to adopt in order to improve their fitness levels. Many of these women walked (often great distances) and engaged in physical work (piece jobs, kitchen staff, agriculture, and other) but expressed the desire to engage in alternative and more proactive forms of physical exercise.

These results depict a fairly homogenous distribution of side effects. The largest number of responses was found on the item physical fitness, with at least $50 \%$ of respondents reporting an improvement on this item. The majority of respondents were positive about their treatment. The largest self-reports of side effects were lipodystrophy, with an average of $6.5(35 \%)$ of the sample of 20 reporting the presence of lipodystrophy.

These interviews and facility visits provided support for the arguments that:

- Advances made in ARV treatment have significantly improved patients' quality of life, self-esteem, overall positive attitudes and perceptions, confidence, motivation, 
self-determination, and reduced depression and other related mood disorders.

- There is, however, a degree of body self-image anxiety related to overall health, disability, and appearance in this population.

- Needs analysis: there is a need for complementary care programs, including education around the importance of exercise, to help these women address and identify some of these areas. This would include specific disability and appropriate intervention (ie, specialty exercise programs such as resistive/enactive kinetics), as well as to improve overall fitness, health, and body self-image.

Responses of the qualitative analysis from the interviews were all related to the questions in accordance with the research question. Of particular importance, however, is the fact that even though more questions pertaining to HIV and AIDS could have been discussed (answered) per se, answers to those questions that were asked provided valuable input. Thus, the results of the qualitative analysis from these interviews are in agreement with related themes from the literature overview and in particular with the theoretical framework and aims of the study.

\section{Results for Stage 2}

The body of literature in this study focused upon the effect that physical side effects of ART, such as metabolic disorders (lipodystrophy and physical disfigurement), have on the psychological well-being and mental health of the HIV sufferer. It became apparent during these initial stages of the research that women receiving ART require complementary psychosocial support such as mental health interventions, alternative counseling strategies, and services. It was also discovered that HIV-infected individuals are still vulnerable to pervasive stigma and misconceptions surrounding the disease. This fills them with feelings of shame and guilt, which lead to a reduced self-esteem and unhealthy mental states. ${ }^{18}$ Women possess and guard the right to childbearing. However, HIV-positive pregnant women may experience depressing and suicidal thoughts, as HIV-related stigma and discrimination govern their lives. To ensure adherence to ART, improve treatment success, and reduce these stigmas, it is necessary to identify and ascertain the impact on HIVpositive individuals.

Stage 2 of this study comprised a quantitative, experimental design conducted at three primary care clinics in Johannesburg, South Africa. The respective diagnostic tools (self-report questionnaires) were deployed to assess the impact of ARVs at both physical and psychological levels. ${ }^{20}$

\section{Sample}

A sample of $60(\mathrm{~N}=60) \mathrm{HIV}$-infected women, aged between 20 and 60 (mean age 39) years, were selected from three primary care outpatient clinics in the Johannesburg area. Participants were randomly assigned to the experimental and control groups. Participants had a mean body mass index (BMI) of $23.4 \mathrm{~kg} / \mathrm{m}^{2}$ and collectively had a mean of 5.5 years receiving ART.

The aim of Stage 2 was to measure the relationship between the dependent variable (movement therapy program) and the two dependent variables (depression and body self-image) over a 6-week duration period. Biographic and screening questionnaires were deployed, in order to gain information around participants' medication (regimen 1 vs older regimen 2), attitudes toward exercise, and presence of physical side effects, such as metabolic disorders (lipodystrophy and lipoatrophy). The experimental design comprised of a pre- and posttest, assessing the depression and body self-image of the participants. Correlates of depression and body self-image in HIV-infected women - with age, HIV disease stage, years (time) on ARVs, socioeconomic, and other factors, as well as the associations between other potential predictor variables were tabulated. The ethnic groupings of participants are depicted in Table 2.

These results indicated that lipodystrophy was more likely to be present in participants receiving the older (regimen 2) ART, as $71 \%(n=20)$ of participants presenting with lipodystrophy were in this category, while only $22.2 \%(n=4)$ were receiving the new single-dose ART (regimen 1, as shown in Table 3). These outcomes suggest that the new regimens of ART have notably reduced the occurrence of metabolic disorders such as lipodystrophy. There was no statistical measurement of toxicity, CD4 counts, or viral loads posttest.

\section{Stage 2 - experimental design \\ Questionnaires}

In line with the aims of this study, we decided to use $\mathrm{BDI}^{6}$ and Rowe's ${ }^{33}$ BSIQ for the quantitative section of the study.

\section{Beck's depression inventory}

The $\mathrm{BDI}^{6}$ was originally proposed as a measuring tool for depression. A significant aspect of the $\mathrm{BDI}^{6}$ is that depression can be thought of as having two components: an affective

Table 2 Ethnic grouping of the sample

\begin{tabular}{lll}
\hline Ethnic grouping & $\mathbf{N}$ & Percent \\
\hline Black & 52 & $86 \%$ \\
Colored & 7 & $12 \%$ \\
Indian & 1 & $2 \%$ \\
\hline
\end{tabular}

Note: The majority of participants $(86 \%)$ were black South African women, receiving ART.

Abbreviation: ART, antiretroviral treatment. 
Table 3 Cross tabulation - presence of lipodystrophy in relation to ARV regimen

\begin{tabular}{cllll}
\hline ARV regimen & Participant & \multicolumn{2}{l}{ Lipodystrophy } & Total \\
& percentage & & & \\
\hline \multirow{4}{*}{ Regimen I } & Count & 35 & 10 & 45 \\
& \% within regimen & 77.8 & 22.2 & 100.0 \\
& \% within lipodystrophy & 89.7 & 50.0 & 76 \\
& \% of total & 59.3 & 16.9 & 76.3 \\
Regimen 2 & Count & 4 & 10 & 14 \\
& \% within regimen & 28.6 & 71.4 & 100.0 \\
& \% within lipodystrophy & 10.3 & 50.0 & 23.7 \\
Total & \% of total & 6.8 & 16.9 & 23.7 \\
& Count & 39 & 20 & 59 \\
& \% within regimen & 66.1 & 33.9 & 100.0 \\
& \% within lipodystrophy & 100 & 100 & 100 \\
& \% of total & 66.1 & 33.9 & 100 \\
\hline
\end{tabular}

Abbreviation: ARV, antiretroviral.

Table 4 Descriptive statistics for depression: BDI ${ }^{6}$

\begin{tabular}{llllll}
\hline BDI & Pretest & & & Posttest \\
\cline { 2 - 3 } \cline { 6 - 6 } & Mean & SD & & Mean & SD \\
\hline Experiment & 6.17 & 3.97 & & 4.85 & 2.85 \\
Control & 4.64 & 2.79 & & 2.75 & 2.10 \\
\hline
\end{tabular}

Abbreviations: BDI, Beck's depression inventory.

component (mood) and a somatic component (ie, loss of appetite, inertia). The internal consistency for the $\mathrm{BDI}^{6}$ is high, with a Cronbach's alpha coefficient of 0.80 , reported by Beck and Steer, ${ }^{7}$ and 0.85 reported by Ambrosini et al, ${ }^{1,13}$ meaning that the items on the inventory are highly correlated with each other. A confirmatory factor analysis of the Beck Anxiety and BDI items in depressed clients suggests that a single factor of negative affectivity more accurately represents the questionnaire items. The scores obtained by participants in the BDI were interpreted according to the BDI-II manual ${ }^{6}$ as follows:

\section{Descriptive results for depression according to $\mathrm{BDI}$}

Analysis of the $\mathrm{BDI}^{6}$ included both descriptive and nonparametric statistical testing. On examining depression by group (for skewness, normal distribution), the results did not show a normal distribution, as the Kolmogorov-Smirnov statistic was statistically significant for the experimental $(p=0.011)$ and control groups $(p=0.001)$, respectively. It was decided to use the results of the nonparametric test results, namely the Wilcoxon signed-rank (within groups) and Mann-Whitney (between groups) comparisons. Cronbach's alpha scores indicated acceptable internal consistency during pretesting for the BDI $(\alpha=0.612)$.

Due to the fact the statistical differences between the means for the two groups (pre- and posttest) were relatively small and taking into account the small sample $(\mathrm{n}=55)$, as shown in Table 4, effect sizes were included in the analysis.
Effect sizes for the nonparametric Wilcoxon signed-rank tests were calculated according to the formula $r=Z / \sqrt{ } N$, where $r$ is the mean of the ranks, $N$ is the total number of the samples, and $Z$ is the critical value of statistical significance, i.e. 1.96.

The descriptive results for both groups are presented earlier, indicating that both the experimental and control groups were not noticeably depressed at the start of the research. Scoring on the $\mathrm{BDI}^{5}$ indicates the following:

- 1-10: These ups and downs are considered normal

- 11-16: Mild mood disturbance

- 17-20: Borderline clinical depression

- 21-30: Moderate depression

- 31-40: Severe depression

- >40: Extreme depression

The majority of scores $(92 \%)$ on the $\mathrm{BDI}^{6}$ ranged between 1 and 16 for both groups, and there were no items that denoted instances of borderline to extreme depression. Posttest outcomes showed a relatively slight decrease in mean scores (decrease in depression) for both experimental and control groups, as a result of the intervention. These outcomes were therefore statistically significant. The reason for this could be ascribed to a range of extraneous variables. These outcomes suggest the possibility that participants of Stage 2 did not fully comprehend 1) the wording of the questions of the BDI, ${ }^{6}$ suggesting questionnaire bias and/or 2) did not actually associate with the feelings and emotions around depression as a construct.

This is in contrast to studies ${ }^{4,24}$ that depict decreases in depression through exercise programs in Westernized populations. Further research in this regard is thus suggested for future studies on women who present with diagnosable or diagnosed depression.

\section{BSIQ}

The BSIQ (short version) ${ }^{30}$ comprises 27 items with a 5-point Likert-scale response for each item. Previous studies around body self-image found that body self-image could be categorized into items that were cognitively perceived (predeterministic ideation, refutable or subject to change) vs attitudinal and affective (deterministic ideation, not subject to change directly). Items of the BSIQ were therefore divided into two categories: cognitive-perceptual (I think my body is unattractive) vs affective-attitudinal (My body feels fat or overweight/I regard myself as fat).

The results present nine evaluative subscales related to body image, namely:

- Overall appearance evaluation: this subscale comprises a self-report on overall appearance and includes questions 
such as "I think my body is unattractive" (cognitive perceptual)

- Fatness evaluation: this subscale comprises a self-report on (perception of) fatness and includes questions such as "my buttocks are fat" (cognitive perceptual) (affective attitudinal). Bearing in mind that cultural norms differ from region to region in SSA.

- Health/fitness evaluation: this subscale comprises a selfreport on overall health and fitness and includes questions such as "my body looks/feels healthy" (affective attitudinal)

- Negative affect: this subscale comprises a self-report on negative feelings (affect) about the body and includes questions such as "my body makes me depressed" (affective attitudinal)

- Health/fitness influence: this subscale comprises a selfreport on factors which influence health and fitness such as "my body feels good when I exercise" (affective attitudinal)

- Social desirability: this subscale relates to participants' concerns about the opinions of other (including prejudice and stigma) and includes questions such as "I worry about what others think of me" (cognitive perceptual)

- Investment in ideals: this subscale comprises a self-report on investment in physical ideals such as "I care about the shape of my legs' (affective attitudinal)
- Attention to grooming: this subscale comprises a self-report on grooming appearance and includes questions such as "I care about the way my hair looks" (affective attitudinal)

- Height dissatisfaction: this subscale comprises a selfreport on height satisfaction and includes questions such as "I wish I was taller" (cognitive perceptual)

\section{Results of the BSIQ: affective-attitudinal and cognitive-perceptual items}

The descriptive and nonparametric results of the five affective-attitudinal and four cognitive-perceptual subscales, shown in Table 5, are discussed in the following section.

The difference between the mean for the two groups (pre- and posttest) on each item of the subscale were relatively small, with a small sample size $(n=55)$. Effect sizes were therefore reported for the subscales where there was a significant difference between pre- and posttesting.

\section{Affective-attitudinal subscale}

The following differences were noted as shown in Table 5: there was a statistical significance (after the specialty exercise program), in two of the experimental groups, namely for negative affect and health fitness evaluation. The mean differences (posttest) for these two groups were marginal. It is suggested (see Discussion) that there are two reasons for this:

Table 5 Descriptive statistics for the BSIQ (Rowe, 199933) cognitive-perceptual and affective-attitudinal subscales

\begin{tabular}{|c|c|c|c|c|c|c|}
\hline \multirow[t]{2}{*}{ BSIQ } & \multirow[t]{2}{*}{ Subscale } & \multirow[t]{2}{*}{ Group } & \multicolumn{2}{|c|}{ Pre-test } & \multicolumn{2}{|c|}{ Post-test } \\
\hline & & & Mean & SD & Mean & SD \\
\hline \multirow[t]{10}{*}{ Affective-attitudinal } & AG & Exp & 12.23 & 1.45 & 11.78 & 1.79 \\
\hline & & Ctrl & 11.93 & 2.04 & 11.34 & 3.59 \\
\hline & II & Exp & 11.63 & 1.77 & 11.10 & 1.56 \\
\hline & & Ctrl & 11.60 & 1.39 & 10.27 & 3.21 \\
\hline & $\mathrm{HFI}$ & Exp & 12.16 & 1.68 & 12.50 & 1.29 \\
\hline & & Ctrl & 11.83 & 1.57 & 11.20 & 3.49 \\
\hline & NA & Exp & 7.46 & 2.37 & 6.46 & 2.08 \\
\hline & & Ctrl & 6.43 & 1.90 & 5.62 & 2.49 \\
\hline & HFE & Exp & 9.36 & 1.60 & 10.53 & 1.59 \\
\hline & & Ctrl & 10.63 & 1.56 & 9.44 & 3.08 \\
\hline \multirow[t]{8}{*}{ Cognitive-perceptual } & OAE & Exp & 11.00 & 2.00 & 11.89 & 1.85 \\
\hline & & Ctrl & 12.30 & 1.62 & 11.79 & 2.09 \\
\hline & HD & Exp & 3.66 & 0.92 & 4.46 & 1.45 \\
\hline & & Ctrl & 4.10 & 1.09 & 3.75 & 1.66 \\
\hline & SD & Exp & 9.20 & 1.09 & 8.00 & 1.82 \\
\hline & & Ctrl & 8.46 & 1.61 & 7.44 & 2.75 \\
\hline & $\mathrm{FE}$ & Exp & 6.90 & 2.30 & 5.92 & 1.60 \\
\hline & & Ctrl & 6.10 & 1.42 & 5.17 & 2.08 \\
\hline
\end{tabular}

Abbreviations: BSIQ, body self-image questionnaire; AG, attention to grooming; Exp, experimental; Ctrl, control; II, investment in ideals; HFI, health/fitness influence; NA, negative; HFE, health/fitness evaluation; OAE, overall appearance evaluation; HD, height dissatisfaction; SD, social desirability; FE, fatness evaluation. 
1. Participants of both groups did not have a low body selfimage per se, as a function of their culture and overall satisfaction with their bodies.

2. Participants may not have fully comprehended the relevance of questionnaire items (questionnaire bias).

\section{Cognitive-perceptual subscale}

The item of the cognitive-perceptual subscales which showed statistical significance was social desirability, as shown in Table 5. This may be associated with the way the sample perceived themselves with regard to others' opinions of them in the societal context (prejudice, stigma related to HIV and AIDS).

\section{Discussion}

The outcomes of this research study validated a number of empirical constructs, thought to contribute to vital areas of research into HIV. From the supportive literature and arguments which constituted the premises of this study, it became apparent that women in SSA are adversely affected by the metabolic side effects of ART, which in turn leaves them at risk of developing self-image and mood disorders. The cultural context and issues of ethnicity were explored, in terms of attitudes to exercise, body satisfaction, and mental and physical wellness. Results from both stages of the study provided evidence, in line with global health mandates $\left(\mathrm{WHO}^{45-47}\right.$ and $\mathrm{UNICEF}^{39}$ mandates), that there is indeed a need for more integral complementary care and therapeutic programs to enhance the physical and psychological well-being of HIV sufferers who are receiving ART and experiencing negative side effects.

The qualitative section of the study (UNFPA AIDS Inventory outcomes $)^{46}$ provided information and outcomes about: 1) HIV sufferers' willingness to engage in complementary care and therapeutic programs of this nature and 2) the desire for a specialty exercise program aimed at improving their body shape and size. Concerns around metabolic disorders, as a function of lipodystrophy, were found to be an important factor in the desire for overall well-being of the HIV suffers.

Stage 1 of this study gained support via Stage 2 (the quantitative experimental design) of this study, which provided evidence that the sample displayed (minimally) reduced levels of both depression (BDI) ${ }^{6}$ and low body self-image. The result of the $\mathrm{BSIQ}^{33}$ indicated (minimal) improvement on the item negative affect. Both outcomes are related to participant's engagement in the therapeutic exercise program (cognitive kinetics). Results on the item indicating social desirability implied participants' desire to improve body shape and appearance, as a function of their status in their communities. This item plays a role in both perceived and real stigma, experienced by these women.

\section{Limitations of the study - cultural bias}

A secondary area of interest gained from this study is that, after brief interviewing (at clinics and provincial district hospitals in three SSAs), it was found that participants did not appear to conceptualize the exact meaning of depression or body self-image. Further to this, although they liked and enjoyed exercise, they were unsure of how this would apply to them, as many of them had physical- or labor-oriented jobs and also walked very long distances to and from home and work.

Descriptive results of Stage 1 (qualitative) of this study therefore showed that participants likely did not clearly grasp the semantic constructs of either the questionnaire or the meaning of mood disorders such as depression and could therefore not report on such.

Similarly, results of Stage 2, comprising the quantitative analysis, showed a minimal difference in depression, as a result of BDI. ${ }^{6}$ Bearing in mind that participants spoke different African languages and came from diverse cultures, some of them did not seem to clearly grasp BDI questions or phrases, such as "I feel suicidal/feel like killing myself", and it was found that many of them did not seem to have a comprehension of depression per se. This brings into question the possibility of questionnaire bias, but also again begs the question as to the extent to which women in Africa perceive or conceptualize the construct of depression per se. Further to this, with regards to Stage 2, which comprised a quantitative analysis of depression and body self-image, using both $\mathrm{BDI}^{6}$ and the $\mathrm{BSQI},{ }^{33}$ there were only minimal changes in the two sections of body self-image, namely perceptual-cognitive and affective-attitudinal.

In terms of cultural norms and values around body weight, shape, and size, it further became apparent that participants had varying perceptions, attitudes, and feelings about their bodies. It is thought that this could be a result of the following:

1. Questionnaire bias, bearing in mind that the screening instruments are designed for Western subjects and are open to linguistic interpretation and bias. ${ }^{12}$

2. Language barriers - did not understand the questions and/ or the contextual meaning of what depression comprises. ${ }^{19}$

3. Did not actually succumb to depression, and their lifestyle in resource-strapped countries allows less concentration on such constructs - dictates different norms, values, and work ethics. 
4. Extraneous variables - external factors which prevented them from expressing themselves concisely, possibility of feeling self-conscious, unsure, or unwilling to divulge personal information.

\section{Conclusion}

This study validated the importance of alternative complementary care interventions, in line with global health mandates of $\mathrm{WHO}^{45,47}$ and UNICEF, ${ }^{39}$ mandates for the improved quality of life of HIV-positive individuals. It was found that depression was impacted positively by the therapeutic exercise program, as were certain aspects of body self-image. Evidence was therefore provided that this type of intervention offers the HIV sufferer effective tools for resolving some of the issues surrounding their disease. It is also believed that the more knowledge patients, careworkers, and individuals have regarding both the side effects and related psychological disorders of their disease, the more effectively this population will be able to self-manage and self-regulate their behavior.

\section{Author contributions}

I hereby state that myself, as primary researcher, Dr AK Daniels, am the sole originator of all content. My supervisor Professor R L Van Niekerk provided support and professional guidance during this process. Both authors contributed toward data analysis, drafting and revising the paper and agree to be accountable for all aspects of the work.

\section{Disclosure}

The authors report no conflicts of interest in this work.

\section{References}

1. Ambrosini P, Metz C, Bianchi M, Rabinovich H, Undie A. Concurrent validity and psychometric properties of the Beck depression inventory in outpatient adolescents. JAACAP. 1991;30(1):51-57.

2. Andersen L, Seedat S. Mental health services for HIV/AIDS patients are long overdue. S Afr Med J. 2009;99(11):796.

3. Avert. HIV and AIDS in South Africa/ Tanzania. 2016. Available from: https://www.avert.org/professionals/hiv-around-world/sub-saharanafrica/tanzania. Accessed May 11, 2018.

4. Barnhart M, Shelton J. ARVs: the next generation. Going boldly together to new frontiers of HIV treatment. Global Health Sci Prac. 2015;3(1): $1-11$.

5. Basu S, Chwastiak LA, Bruce R D. Clinical management of depression and anxiety in HIV-infected adults. AIDS. 2005;19(18):2057-2067.

6. Beck A, Ward C, Mendelson M, Mock J, Erbaugh J. An inventory for measuring depression. Arch Gen Psych. 1961;4(6):561-571.

7. Beck AT, Steer RA, Brown GK. Manual for the Beck Depression Inventory-II. San Antonio, TX: Psychological Corporation; 1996.

8. Bendavid E, Holmes C, Battachary J, Miller G. HIV development assistance and adult mortality in Africa. JAMA. 2012;307(19): 2080-2087.

9. Brug J, Hospers H, Kok G. Differences in psychosocial factors and fat consumption between stages of change for fat reduction. JPMH. 1997;12:719-727.
10. Calmly A, Cooper D, Hirschel DA, Carr D. Clinical update: the adverse effects of anti-retroviral therapy. Lancet. 2007;370(12):14.

11. Calmly A, Ford N, Hirschel B, et al. HIV viral load monitoring in resource-limited regions: optional or necessary? Clin Infect Dis. 2007;44(1):128-134.

12. Clark L. Qualitative research, meaning and language. $J A d v$ Nursing. 1992;17:243-225.

13. Enns M, Cox B, Parker J, Guertin J. Confirmatory factor analysis of the Beck Anxiety and Depression inventories in patients with major depression. J Aff Dis. 1998;47(1-3):195-200.

14. Farinatti P, Borges J, Gomes R, Kima D, Fleck, S. Effects of a supervised exercise program on the physical fitness and immunological function of HIV-infected patients. J Sports Med Phys Fitness. 2010;50(4):511-518.

15. Gallant JE, DeJesus E, Arribas JR, et al. Tenofovir DF, emtricitabine, and efavirenz vs. zidovudine, lamivudine, and efavirenz for HIV. N Eng J Med. 2006;19:354(3):251-260.

16. Goff D, Lloyd-Jones D, Bennett G, et al. ACC/AHA guideline on the assessment of cardiovascular risk. A report of the American College of Cardiology/American Heart Association task force on practice guidelines. J Am Coll Card. 2013;63(25B):2935-2959.

17. King M, Bruner G. Social desirability bias: a neglected aspect of validity testing. Psychol Market. 2000;17(2):79-103.

18. Kontomanolis E, Michalopoulos S, Gkasdaris G, Fasoulakis Z. The social stigma of HIV-AIDS: society's role. HIV AIDS. 2017; 9:111-118.

19. Makhubela MS, Mashegoane S. Validation of the Beck depression inventory-II in South Africa: Factorial validity and longitudinal measurement invariance in university students. SAJP. 2015;46(2): 203-217.

20. MacCarthy S, Hoffmann M, Ferguson L, et al. The HIV care cascade: models, measures and moving forward. J Int AIDS Soc. 2015;18(1):19395.

21. Mangona L, Daca T, Tchonga F, et al. Effect of different types of exercise in HIV + Mozambican women using antiretroviral therapy. Open AIDS J. 2015;9: 89-95.

22. Nachega J, Stein B, Lehman DA. Treatment simplification in HIVinfected adults as a strategy to prevent toxicity, improve adherence, quality of life and decrease healthcare costs. AIDS Res Hum Retroviruses. 2004;20(10):1053-1056.

23. O'Brien K, Bayoumi A, Strike C, Young N, Davis A. Exploring disability from the perspective of adults living with HIV/AIDS: development of a conceptual framework. Health Qual Life Outcomes. 2008;6:76.

24. O'Brien K, Tynan A, Nixon S, Glazier R. Effects of progressive resistive exercise in adults living with HIV/AIDS: systematic review and meta-analysis of randomized trials. AIDS Care. 2008;20(6):631-653.

25. Ortiz A. Exercise for adults living with human immunodeficiency virus infection in the era of highly active antiretroviral therapy. Int $J$ Phys Med Rehab. 2014;2(4):213.

26. Ownby R, Jacobs R, Waldrop-Valverde D, Gould F. Depression care and prevalence in HIV-positive individuals. JNeur HIV Med. 2010; (2):73-83.

27. Orza L, Bewley S, Logie CH, et al. How does living with HIV impact on women's mental health? Voices from a global survey. J Int AIDS Soc. 2015;18(Suppl 5):20289.

28. Petruzzello S, Landers D. Physical Activity, Fitness, and Health. International Proceedings and Consensus Statement. Champaign, IL: Human Kinetics Publishers; 1994.

29. Pirmohamed M, Chapanda C. Hypersensitivity reactions in HIV therapy. J Clin Pharm. 2011;71(5):659-671.

30. Portney L, Watkins M. Foundations of Clinical Research. Upper Saddle River, NJ: Prentice Hall Health; 2000.

31. Ramjee G, Daniels B. Women and HIV in sub-Saharan Africa. AIDS Res Ther. 2013;10(1):30.

32. Roubenoff R, Skolnik P, Sheritz A, Snyman L, Wang A. Effect of a single bout of acute exercise on plasma human immondeficiency virus RNA levels. J Appl Phys. 1998;86(4): 1197-1201.

33. Rowe DA, Benson J, Baumgartner TA. Development of the body selfimage questionnaire. Meas Phys Educ Exerc Sci. 1999;3(4):223-247.

34. South African National AIDS Council (SANAC). The people living with HIV Stigma Index: South Africa - Summary Report May 2015. 2015. 
35. Spies M. The biopsychosocial factors influencing HIV/AIDS patient adherence to antiretrovirals. University of Pretoria. Int J Meth Psych Res. 2007;11:75-82.

36. Steele GI. The development and validation of the Xhosa translations of the Beck depression inventory, the Beck Anxiety Inventory, and the Beck Hopelessness Scale. Biblioteca Universia. 2006. Available from: http:// biblioteca.universia.net/ficha.do?id=12575724. Accessed May 11, 2018.

37. Terry L, Sprinz E, Stein R, Medeiros NB, Oliveira J, Ribeiro JP. Exercise training in HIV-1-infected individuals with dyslipidemia and lipodystrophy. Med Sci Sports Exerc. 2006;38(3):411-417.

38. Tiggeman M, Williamson $\mathrm{S}$. The effect of exercise on body satisfaction and self esteem as a function of age and gender. Sex Roles. 2000;43:119-127.

39. UNICEF. Achieving an AIDS-free generation: UNICEF's HIV/AIDS programme vision and direction for action 2014-2017. 2013.

40. Van den Berg H, Manstead A, Van der Pligt J, Wigboldus DH. The impact of affective and cognitive focus on attitude formation. $J \operatorname{Exp}$ Soc Psychol. 2006;42:373-379.

41. Van Ness F, Abma T, Jonsson H, Deeg D. Language differences in qualitative research: is meaning lost in translation? Eur J Ageing. 2010;7(4):313-316.

42. Vaccaro G, Lavick J. Trauma: frozen moments, frozen lives. BETA. 2008;20(24):31-41.
43. Vermund SH, Fidler SJ, Ayles H, Beyers, N, Hayes RJ. Can combination prevention strategies reduce HIV transmission in generalized epidemic settings in Africa? The HPTN 071 (PopART) study plan in South Africa and Zambia. J. Acquir Imm Defic Synd. 2013;63(Suppl 2): S221-S227.

44. Whiting D. Review of Michelle Maiese. Embodiment, emotion and cognition. Notre Dame Philos Rev. 2011. Available from: https://ndpr. nd.edu/news/embodiment-emotion-and-cognition/. Accessed May 11, 2018.

45. World Health Organization (WHO), United Nations Population Fund (UNFPA), Joint United Nations Programme on HIV/AIDS (UNAID), and the International Planned Parenthood Federation I (IPPF). Linking Sexual and Reproductive Health and HIV/AIDS: An annotated inventory. 2005. Available from: http://www.who.int/reproductivehealth/ publications/rtis/inventory_linkages_shr_hiv.pdf. Accessed May 11, 2018 .

46. World Health Organisation/UNFPA. UNFPA annual report: millions of lives transformed. 2016. Available from: https://www.unfpa.org/ annual-report-2016. Accessed May 11, 2018.

47. World Health Organisation. Women at the centre: WHO issues new guidance on the sexual and reproductive health and rights of women living with HIV: gender equality and human rights are key to ensuring well-being and dignity for women living with HIV. 2017.
HIV/AIDS - Research and Palliative Care

\section{Publish your work in this journal}

HIV/AIDS - Research and Palliative Care is an international, peerreviewed open access journal focusing on advances in research in HIV, its clinical progression and management options including antiviral treatment, palliative care and public healthcare policies to control viral spread. The journal is included in PubMed. The manuscript

\section{Dovepress}

management system is completely online and includes a very quick and fair peer-review system, which is all easy to use. Visit http://www.dovepress.com/testimonials.php to read real quotes from published authors. 